\title{
OPINION
}

\section{Impressions of defensive medical practice and medical litigation among South African neurosurgeons}

\author{
D Roytowski, T R Smith, A G Fieggen, A Taylor
}

David Roytowski, Graham Fieggen and Allan Taylor all work in the Division of Neurosurgery, Faculty of Health Sciences, University of Cape Town, South Africa. Timothy Smith is from the Department of Neurological Surgery at Northwestern University in Chicago, Illinois, USA.

Corresponding author: A Taylor (allan.taylor@uct.ac.za)

From a litigation perspective, neurosurgery is considered a 'super high-risk' field, and this has been associated with rapidly increasing malpractice cover costs. In 2013 the annual Medical Protection Society fee for cover was R250 900. We wished to determine whether high malpractice cover was influencing how neurosurgeons managed patients. A 40-question online survey asking questions on defensive medicine was distributed to determine perceptions around liability risk and whether these influenced how patients were managed. Eightyfour per cent of respondents agreed that a medicolegal crisis existed, and over half (53.8\%) had been sued for malpractice during their career Altering practice behaviour to minimise the risk of a lawsuit is common. The increasing number of legal claims against respondents in this survey has resulted in most neurosurgeons practising defensive medicine. Arguably this will result in increased healthcare costs, inferior patient care and decreased access to skilled surgeons.

S Afr Med J 2014;104(11):736-738. DOI:10.7196/SAMJ.8336

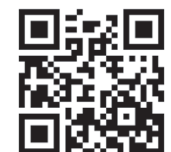

All medical practitioners are at risk of malpractice claims, but fields involving acute illness where rapid decision-making is required and outcomes may be unavoidably poor are at more risk of attracting litigation. Neurosurgery is one of those fields. ${ }^{[1}$ The annual premium charged by the Medical Protection Society for malpractice cover has increased three-fold between 2008 and 2013, with neurosurgery now classified as 'super high risk'. The annual premium (R250 900 for 2013) is second only to that for obstetricians (R254 230). ${ }^{[2]}$ This rise in premiums has paralleled the recent increase in the number and amount of awards in malpractice litigation. ${ }^{[3]}$ The scale of the problem is reflected in South Africa's highest-ever medical damages settlement of R25 million in June 2013, to a patient who had undergone neurosurgery. ${ }^{[4]}$

The net result of increased litigation and increased premiums is thought to have several consequences where medical practice is concerned:

- A change in practice to more defensive behaviour, with the effect of increasing costs to patients and funders, ultimately driving up healthcare inflation ${ }^{[5]}$

- Limiting practice to patients and conditions that are thought to be 'lower risk' rather than taking on complex or surgically demanding cases $^{[1]}$

- Discouraging specialisation in high-risk disciplines and seeking activities with reduced liability risk, such as non-clinical legal, insurance or road accident fund work.

A recent study in the USA confirmed that neurosurgeons had changed their practice to minimise malpractice risk and that this could ultimately lead to increased costs for patients and reduced access to neurosurgical care. ${ }^{[1]}$

To establish the impact of the medicolegal environment on the behaviours and perceptions of South African (SA) neurosurgeons, a 40-question online survey was distributed to registered SA neurosurgeons. The questions covered seven broad categories, namely surgeon characteristics, patient characteristics, practice type, liability cover aspects, surgeon liability profile, surgeons' perceptions, and defensive practice behaviour.

\section{Findings}

Sixty-six responses were received from neurosurgeons registered to practise in SA. This reflects a $41.7 \%$ response rate from the 158 surgeons contacted. More than $70 \%$ had been in practice for over 10 years. The majority of respondents were from Gauteng $(37.9 \%)$ and the Western Cape provinces (34.8\%).

Sixty-three per cent described themselves as generalist neurosurgeons and a quarter $(26.2 \%)$ as having a spine-dominant practice. A small number described their practice as paediatric, cerebrovascular or functional.

Annual operative caseloads were reported as being between 200 and 300 by $30 \%$, with over a quarter $(26.6 \%)$ reporting more than 10000 cases over their practice lifetime.

Most respondents (72.7\%) were in private practice with just under a quarter $(22.5 \%)$ in state service, of whom two-thirds did some form of limited private practice.

Of the respondents, $18.2 \%$ of respondents did not know whether their institution mandated that they have minimum liability cover, $10.6 \%$ stated they were required to have unlimited cover, and $69.7 \%$ reported that there was no institutional mandate for liability cover. The remainder $(1.5 \%)$ reported a required minimum cover of R1 million - R10 million.

Two-thirds (67.7\%) of the practitioners had an annual cost of indemnity of between R200 000 and R300 000. Three per cent did not have liability cover, and a further $3 \%$ paid in excess of R300 000 .

The cost of malpractice indemnity as a percentage of income varied widely depending on the practice type of the neurosurgeon. Eighty per cent of neurosurgeons in state practice paid less than $5 \%$ of their gross annual revenue (GAR) for malpractice cover (Fig. 1). This probably reflects the fact that some may not have taken any indemnity cover, as the state does not require it, or have cover but pay a reduced fee. Forty per cent of neurosurgeons in limited private practice paid $6-10 \%$ of their GAR for indemnity cover 


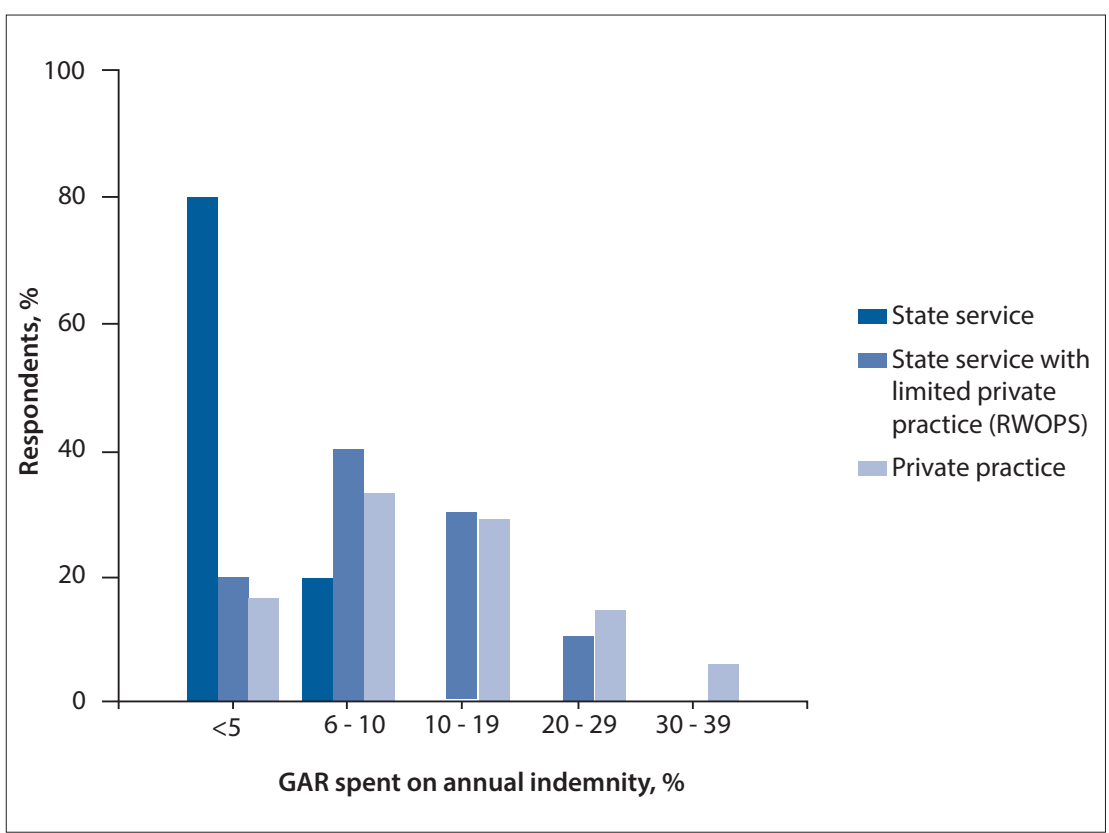

Fig. 1. Malpractice premiums as a percentage of GAR. (GAR = gross annual revenue; RWOPS = remunerative work outside the public sector.)

Sixty-three per cent of private practitioners contributed $6-20 \%$ of their GAR towards their malpractice cover, while $6.3 \%$ paid 30 - 39\%. A single respondent indicated that malpractice indemnity costs constituted $>60 \%$ of his GAR.

Over half $(53.8 \%)$ of the neurosurgeons surveyed had been sued, with $31.8 \%$ of respondents having faced claims in the past 3 years. Just over a quarter $(27.3 \%)$ had faced 1 - 2 claims over the past year, and $4.5 \%$ had faced 3 - 4 claims.

Eighty-four per cent of respondents agreed that there was a medicolegal crisis in their specialty, 6\% disagreed, and the remainder stated that they were neutral.

The majority of the neurosurgeons (58.5\%) indicated that they would have chosen differently if the current medical liability situation had existed when they decided to train in the specialty, $28 \%$ indicated that they would not have chosen a different speciality, and some respondents remained neutral on this issue.

Changing practice behaviour to try to minimise the risk of a lawsuit is a common occurrence. The most common activity undertaken solely to minimise the risk of a lawsuit was requesting imaging studies (when not clinically indicated), with the majority of the respondents (89\%) acknowledging that they had done so. Referring patients was the next most common defensive practice, with $76 \%$ of practitioners claiming to have done so in the past. Sixty-four per cent had ordered extra laboratory tests, and 39\% had prescribed medication that was not clinically indicated. A quarter of the respondents had undertaken a procedure for purely defensive purposes.

Spinal surgery and paediatrics were considered the most risky disciplines with respect to lawsuits. Skull convexity tumour resection was thought to have the lowest risk.

Thirty-one per cent of the neurosurgeons had discontinued providing what they considered to be high-risk procedures owing to the liability that these present.

\section{Discussion}

Medical malpractice litigation is increasing. There are various possible reasons for this, including problems relating to the way doctors treat patients, the expectations of patients, and increased targeting of medical professionals by lawyers. More than 50\% of the neurosurgeons in this survey had been sued, and the data confirm that claim rates are increasing, with the result that almost $90 \%$ of respondents felt that they were practising defensive medicine through ordering unnecessary investigations, referring patients, or doing a procedure that was not clinically required.

Requesting extra investigations has been described as positive defensive practice, implying that despite added cost it can't hurt to be more careful. ${ }^{[6]}$ In our survey the most widely used defensive practice was requesting additional imaging. A classic example would be ordering a magnetic resonance imaging (MRI) scan for a patient presenting with headache. The patient's history and clinical examination may be typical of tension headache, but the doctor can never be $100 \%$ certain. Given the tiny chance that there could be pathology, an MRI scan is requested. This is done so that there can be no accusation of delaying a diagnosis should there be a positive scan finding. The patient may be on a comprehensive medical aid, the scan is fully funded and it shows no abnormality, so everyone is reassured and happy. Even in this good outcome, however, the cost of the scan still has to be paid, and if this happens often enough it will ultimately result in increased medical aid contributions.

The alternative scenario is one where the medical aid does not fully fund the scan, and the patient can't afford the cost either. In this situation the doctor feels safe in that the scan was ordered, but the patient feels more anxious because the responsibility for not having the scan is theirs. A better outcome may result if the doctor feels free to say 'I'm sure this is a tension headache, which we will treat and follow up. A more vexing scenario can occur: MRI shows a small benign cyst that was never the cause of the patient's symptoms. The doctor is convinced about this, but now there is a patient with headache and something on the MRI scan. To avoid potential litigation, the surgeon suggests operating on the cyst (an unnecessary procedure). The costs of this will again reflect in increasing medical aid premiums, with the patient at risk of complications of surgery for an incidental finding. Interestingly, it is precisely this situation that may lead to a lawsuit if the patient develops a surgical complication. Clearly, in this instance defensive practice is bad for both patients and doctors.

Negative defensive practice is seen as avoiding certain patients or procedures. Seventy-six per cent of respondents reported referring patients rather than treating them in order to reduce the risk of litigation. This would typically occur in a field of practice considered high risk, such as paediatric neurosurgery. Unfortunately in SA, because of spiralling malpractice cover costs, paediatric neurosurgeons have withdrawn from private practice altogether. Although this information did not come directly from the survey, it came to light during subsequent discussions initiated by the survey. Private patients may still consult these specialists, but only at a state hospital, which increases the burden on already overstretched facilities. Concern has been raised that obstetricians will be unwilling to perform deliveries in the private sector by the end of the decade as a result of risk 
avoidance ${ }^{[7]}$ Given the experience in neurosurgery, this is a real concern that will ultimately impact on other disciplines.

Almost $60 \%$ of respondents would not choose to train in neurosurgery if they were starting over; sadly, this attitude is likely to filter to prospective trainees. We face a future in which there may not be a specialist to remove the extradural bleed from a child who has fallen off a swing, or decompress the nerve crushed by a disc fragment in a patient who is in unbearable pain.

This survey confirms that there is a crisis in neurosurgery, and probably also in other practices considered super high risk. Urgent action is required. There is an obligation for doctors to avoid defensive practice, care for their patients, manage patient expectations and behave as professionals. However, even if doctors were able to address all these points, malpractice litigation would be likely to continue. Unrealistic patient expectations, increased access to malpractice representation through the Contingency Fee Act (No. 66 of 1997) and a shift from road accident fund work to malpractice litigation are all litigation drivers ${ }^{[8]}$ Legal reform in some of the states of the USA is an approach that has helped control personal injury liability costs and could be implemented in SA. ${ }^{[9]}$

\section{Conclusion}

Neurosurgery is considered a super high-risk field in terms of malpractice claims and indemnity cover. The increasing number of legal claims against respondents in this survey has resulted in most neurosurgeons practising defensive medicine. Arguably this will result in higher healthcare costs, inferior patient care, and reduced access to skilled surgeons.

1. Nahed BV, Babu MA, Smith TR, Heary RF. Malpractice liability and defensive medicine: A nationa survey of neurosurgeons. PLoS ONE 2012.7(6):1-7. [http://dx.doi.org/10.1371/journal pone 0039237] 2. Medical Protection Society. MPS Subscription rates (1 January 2013 - 31 December 2013). www. medicalprotection.org/southafrica (accessed 6 December 2013).

3. Howarth GR, Bown S, Whitehouse $S$. The importance of comprehensive protection in today's healthcare environment. S Afr Med J 2013;103(7):453-454. [http://dx.doi.org/10.7196/SAMJ.7106] 4. Botched brain ops lead to SA's highest-ever medical payout. Sunday Times, 16 June 2013.

5. Hermer LD, Brody H. Defensive medicine, cost containment, and reform. J Gen Intern Med 2010;25(5):470-473. [http://dx.doi.org/10.1007/s11606-010-1259-3]

6. Summerton N. Positive and negative factors in defensive medicine: A questionnaire study of general practitioners. BMJ 1995;310(6971):27-29. [http://dx.doi.org/http://dx.doi.org/10.1136/bmi.310.6971.27]

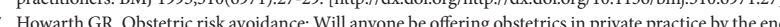
of the decade? S Afr Med J 2013;103(8):513-514 [http://dx.doi.org/10.7196/SAMJ.7233]

8. Malherbe J. Counting the cost: The consequences of increased medical malpractice litigation in South Africa. S Afr Med J 2013;103(2):83-84. [http://dx.doi.org/10.7196/SAMJ.6457]

9. Congression 9. Congressional Budget Office. Limiting Tort Liability for Medical Practice. http://www. bo.gov/sites/

Accepted 1 July 2014. 